\title{
Correlation of Angle SNA to Angle NSAR in Normal Occlusion, Class II Division I and Class III Malocclusion in Vidarbha Region - A Cephalometric Study
}

\author{
Rashmi Jawalekar¹, Pushpa Hazare², Ranjit H. Kamble³, Vikrant V. Jadhav ${ }^{4}$ \\ 1,2 Department of Orthodontics and Dentofacial Orthopaedics, Swargiya Dadasaheb Kalmegh Smriti Dental \\ College and Hospital, Wanadongri, Nagpur, Maharashtra, India, ${ }^{3,4}$ Department of Orthodontics and \\ Dentofacial Orthopaedics, Sharad Pawar Dental College, Wardha, Maharashtra, India.
}

\section{ABSTRACT}

\section{BACKGROUND}

Facial prognathism may be because of prognathic maxilla, prognathic mandible or aggregate of both. Numerous studies performed to diagnose a single morphological feature commonly producing protrusive relationship, revealed that 'a single morphological feature does not ordinarily produce a protrusive relationship. Existence of structural imbalance in one area also affects the nature of balance in other areas. A number of separate but inter-related cause and effect factors tend to augment each other in a cumulative and composite manner. Effect of marked discrepancy of an individual's facial part could be cancelled or nullified by deviation of another part in opposite direction, ultimately resulting in good facial harmony. In this study by means of cephalometric roentgenography, the relation between Angle SNA and Angle NSAr was assessed in Vidharbhites, having normal occlusion, Class II division I and class III malocclusion.

\section{METHODS}

40 individuals of normal occlusion, Class II division I and Class III Malocclusion, each between 16 and 25 years were analysed. These subjects were selected from patients reporting the outpatient department of Government Dental College, Nagpur. Statistically correlation between angles SNA and NSAr at level of significance $5 \%$ was assessed.

\section{RESULTS}

After data collection a thorough observation \& analysis was done and co-relation coefficient between SNA angle \& NSAr (F--1.054 M--0.7981), also standard deviation of angular cephalometric measurement between males \& females was found out in the population, leading to discussion on topic 'Facial prognathism is due to maxillary prognathism, mandibular prognathism or combination of both'. In Females SNA was found to be $81-80^{\circ} 1.9131^{\circ}$ and in males SNA was $82.166^{0} 4.380$ respectively.

\section{CONCLUSIONS}

The results inferred that "Marked part of variation in Angle SNA can be explained by variation in Angle NSAr.

\section{KEY WORDS}

Angle SNA, Angle NSAr, Correlation
Corresponding Author: Dr. Rashmi Jawalekar, Professor and HOD., Department of Orthodontics and Dentofacial Orthopaedics, Swargiya Dadasaheb Kalmegh Smriti Dental College and Hospital, Wanadongri, Nagpur, Maharashtra, India.

E-mail: rashmi.jawalekar@sdk-entalcollege.edu.in DOI: $10.14260 /$ jemds/2021/522

How to Cite This Article:

Jawalekar R, Hazare P, Kamble RH, et al. Correlation of angle SNA to angle NSAR in normal occlusion, class II division I and class III malocclusion in Vidarbha region a cephalometric study. J Evolution Med Dent Sci 2021;10(32):2543-2547, DOI: 10.14260/jemds/2021/522

Submission 28-12-2020,

Peer Review 08-06-2021,

Acceptance 16-06-2021,

Published 09-08-2021.

Copyright (C) 2021 JEMDS. This is an open access article distributed under Creative Commons Attribution License [Attribution 4.0 International (CC BY 4.0)] 


\section{BACKGROUND}

ANB (A point, nasion, B point) indicates whether the skeletal relationship between the maxilla and mandible is a normal skeletal class I ( +2 degrees), a skeletal Class II $(+4$ degrees or more), or skeletal class III (0 or negative) relationship. SNA (sella, nasion, a point) indicates whether or not the maxilla is normal, prognathic, or retrognathic. SNB (sella, nasion, B point) indicates whether or not the mandible is normal, prognathic, or retrognathic. SNA and SNB are important to determine what type of intervention (on maxilla, mandible, or both) is appropriate. These angles, however, are influenced by the vertical height of the face and a possible abnormal positioning of nasion. By using a comparative set of angles and distances, measurements can be related to one another and to normative values to determine variations in a patient's facial structure.

No part of human anatomy has gained so much importance as does the face. For centuries men have sought to resolve the riddle of facial beauty and harmony through measurements and geometry. Wendel $\mathrm{Wylie}^{1}$ believes that dentofacial anomalies occur due to random combination of various individual facial parts. A given part may be normal in all aspects but may produce dysplasia if each of the facial part fits badly with another. Discrepancy of individual facial part can be nullified by deviation of another part in opposite direction, ultimately resulting in good facial harmony.

Malocclusions in sagittal plane are highly predominant and have functional, aesthetic, and social implications that make them a public health issue. Their prognosis and clinical expression in adulthood are determined by the growth of face.

Facial growth is a complex phenomenon characterized by the differential development of the jaws. Therefore, the sagittal intermaxillary relationship varies gradually between an early age and adulthood where normal young individuals have a greater facial convexity than adults.

A cephalometric measurement most commonly used to diagnose sagittal skeletal dysplasias is the ANB angle. It is widely used among orthodontists because of its ease of use and consistency with the clinical presentation in most cases. It also performs well as a diagnostic test, with high specificity and sensitivity assessing sagittal intermaxillary discrepancies.

Clinically, the ANB angle is often used thinking about the mean value of $2^{\circ}$ and preferred deviation of $2^{\circ}$. However, this diagnostic method neither considers the maturational status of patient, nor does it take into account the possibility of a variant in the sagittal intermaxillary relationship throughout facial development. An early evaluation, which fails to recollect the above-stated developmental pattern, could incorrectly classify an individual, ultimately leading to an incorrect diagnosis and orthodontic treatment plan. Further, even understanding that a reduction in ANB is anticipated with growth, but the amount of this reduction stays unclear. This is especially problematic in patients growing up with Class II or Class III malocclusions.

In cephalometric analysis, two angles are commonly used. Angle SNA and angle NSAr. Angle SNA is used as an indicator of anteroposterior relationship of maxilla to cranial base and angle NSAr (saddle angle) which is the cranial base angle.
In this study an attempt has been made to analyse by means of cephalometric roentgenography, the relationship between Angle SNA and Angle NSAr in normal occlusion, class II division I and class III malocclusion.

\section{METHODS}

After obtaining informed consent of 40 individuals reporting to outpatient department of Government dental college, with normal occlusion, class II division I and class III malocclusion each, age ranging between 16 and 25 years; as this was the average age of patient reporting to our department and also had full complement of teeth up to second molar with no previous history of orthodontic treatment were analysed. Study was done after the approval from IEC. The study duration was from May 1987 to May 1989.

An observational cross-sectional study with a sample size of 40 individuals based on type of study with a criterion of selection of normal occlusion subjects was purely on subjective basis. Subjects having molars in class II, proclination of upper incisors with increased overjet, and retrognathic profile were selected as subjects with class II malocclusion. Class III malocclusion group had molars in class III, reduced overjet, edge to edge bite or reverse overjet and prognathic profile. Tracing was done with a $2 \mathrm{H}$ pencil on .003" thick tracing paper using following landmarks.

SNA (sella, nasion, point A) - indicates whether or not the maxilla is normal, prognathic, or retrognathic. SNB (sella, nasion, B point) indicates whether or not the mandible is normal, prognathic, or retrognathic.

SNA angle - used to assess anteroposterior position of maxilla relative to anterior cranial base. Normal value is 82 .

NSAr angle - is the angle formed between nasion, sella and articulare. It represents cranial base flexure.

- Skeletal class I -maxilla and mandible are in harmony with each other.

- Skeletal class II -maxilla lies ahead of mandible with reference to anterior cranial base. Maxilla is prognathic.

- Skeletal class III - maxilla lies posterior to mandible with reference to anterior cranial base. Maxilla is retrognathic.

These landmarks were studied, and results were analysed.

\section{RESULTS}

The data collected was analysed statistically, to compare correlation between two angles SNA and NSAr, for both males and females separately. Decision as to the correlation if existed was significant or not was tested by " $t$ " test at a significance level of $5 \%$. The character in normal group was compared to same character in group II and group III. Male and female populations were considered separately.

Before applying " $\mathrm{t}$ " test for testing the significance of the difference between the group means "F" test was carried out and actually verified that these samples have been drawn from the population with same variance. 


\begin{tabular}{|c|c|c|c|c|}
\hline \multirow[t]{2}{*}{ Females } & $\begin{array}{c}\text { SNA } \\
\text { SD }\end{array}$ & $81-80^{0} 1.9131^{0}$ & $82.65^{0} 3.55^{0}$ & $80.66^{0} 2.178^{0}$ \\
\hline & $\begin{array}{l}\text { NSAr } \\
\text { SD }\end{array}$ & $125.30^{0} 3.421^{0}$ & $128.75^{0} 3.226^{0}$ & $121^{\circ} 5.259^{\circ}$ \\
\hline \multirow[t]{3}{*}{ Males } & $\begin{array}{l}\text { SD } \\
\text { SNA } \\
\text { SD }\end{array}$ & $82.166^{0} 4.38^{0}$ & $84.2^{0} 3.7373^{0}$ & $83.46^{0} 2.0076^{0}$ \\
\hline & $\begin{array}{c}\text { NSAr } \\
\text { SD }\end{array}$ & $122.11^{0} 7.6038^{0}$ & $\begin{array}{l}124.65^{0} \\
3.7051^{0}\end{array}$ & $118.15^{0} 6.248^{0}$ \\
\hline & \multicolumn{4}{|c|}{ Table 1} \\
\hline
\end{tabular}

\begin{tabular}{|ccccc|}
\hline & $\begin{array}{c}\text { Normal } \\
\text { Occlusion }\end{array}$ & $\begin{array}{c}\text { Class II } \\
\text { Division I } \\
\text { Malocclusion }\end{array}$ & $\begin{array}{c}\text { Class III } \\
\text { Malocclusion }\end{array}$ \\
In Females & r (SNA, NSAr) & -1.054 & -0.896 & -0.2857 \\
In Males & r (SNA, NSAr) & -0.7981 & -0.32009 & 0.3123 \\
\hline Table 2. Correlation Coefficient of Angular Measurement r $($ SNA, NSAr) \\
\hline
\end{tabular}

\begin{tabular}{|ccc|}
\hline Type & In Females & In Males \\
Normal Occlusion & 2.10 tabulated $-.4496^{*}$ & 2.12 tabulated -3.72 \\
& calculated & calculated. \\
Class II Div I & 2.10 tabulated -0.3816 & 2.10 tabulated - \\
& calculated & 1.434 calculated \\
Class III & 2.20 tabulated - & 2.20 tabulated - \\
& 0.9987 calculated & 0.1093 calculated \\
\hline Table 3. " $t$ "Values for Testing Significance of Correlation Coefficients \\
\hline
\end{tabular}

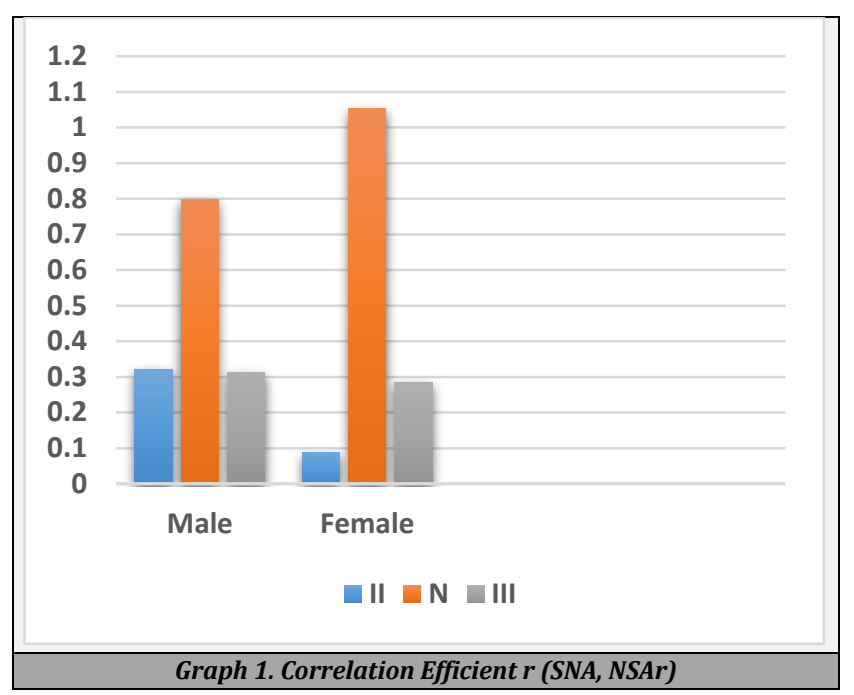

\section{DISCUSSION}

Facial prognathism is due to maxillary prognathism, mandibular prognathism or combination of both. Bjork ${ }^{2}$ 1951, introduced the use of cranial base angle to measure the degree of facial prognathism. He believed NSAr angle had stability similar to Basion. The point articulare had an added advantage of clear visibility on lateral cephalogram. Enlow ${ }^{3}$ studied various combinations among the different sets of part and counterparts contributing towards facial prognathism. Seppo Jervinen ${ }^{4}$ in 1984 observed that in persons with class 1 malocclusion a marked part of variation in the SNA angle can be explained by variation of angle NSAr. Noting these findings, it was decided to find out correlation coefficient ( $\mathrm{r}$ ) between angle SNA and NSAr in all the three groups and deduce the role of cranial 222 base configuration in producing maxillary protrusive effect. In this study the mean angle SNA for normal occlusion group is $81.8{ }^{\circ}\left(\mathrm{SD} 1.91^{\circ}\right)$ in females and $82.16^{0}$ with (SD 4.38 $)$ in males. Table 1 shows that readings of present study for normal occlusion group compared favourably with Steiner's norm. Siddhu ${ }^{5}$ established the norms for Parsees and Maharashtrian subjects between 12 and 18 years, and arrived at a mean value of $81.5^{0}\left(+-5.14{ }^{\circ}\right)$ in females and $82.7^{0}\left(+-7.45^{\circ}\right)$ in males. The readings of present study compared favourably with Steiner's values for normal and Sidhu's norms for Maharashtrians. The mean value of angle SNA in class II div I group was $82.65^{\circ}\left(\mathrm{SD} 3.55^{\circ}\right.$ ) in females and $84.2^{\circ}$ (SD 3.730) in males. The mean in class III, females was 80.6 degrees. In Males it was $83.46^{\circ}\left(\right.$ SD $\left.2.007^{\circ}\right)$

Thus, in class II group value of angle SNA was more than normal for both female and male group. However, it was not significant statistically. The values of angle NSAr in females of normal occlusion group in present study was 125.3 with a standard deviation of $3.42^{\circ}$. In males the value of NSAr was $124.11^{0}$ with standard deviation of $7.6^{0}$. It is observed that values of NSAr were less in both Class II and Class III groups, as compared to values of normal group. SippoJarven in his study of 138 subjects obtained mean value of angle NSAr as $119.77^{0}+5.40^{\circ}$ for normal occlusion, $125.5^{0}+4.5^{0}$ in class II, Div I and 119.770 in Class III malocclusion. Our values of present studies are comparable to his findings. Bjork in 1951 showed small NSAr associated with facial prognathism and large NSAr to be associated with facial retrognathism. In our study values of NSAr are greater in class II group when compared to class III group. This is similar to Bjork findings. Seppo Jarvinen ${ }^{6}$ in his study conducted in 1980 found the values of NSAr in excellent occlusion group to be $121.6^{0}$ with a standard deviation of 5.70 Our values of angle NSAr in normal occlusion group are higher than these values. This can be attributed to the fact that sample size of Jarvinens study was only twenty, also no sex differentiation was considered, in his study.

In the present study the value of NSAr in class II division I group is $124.75^{\circ}$ with standard deviation of $3.72^{\circ}$ in females and it is $122.65^{\circ}$ with standard deviation of $3.705^{\circ}$ in males.

SeppoJarvinen in a similar study of class II Division I samples consisting of 33 females and 28 males from age 9 to 13 years, established the value of $124.3^{0}$ with standard deviation being $5.6^{\circ}$ This value is similar to our values for female group. The value of NSAr in class III females is $118.15^{\circ}$ with standard deviation of $6.24^{0}$. In males it is $121^{\circ}$; standard deviation being 5. 250. SeppoJarvinen in his study of 138 lateral skull radiographs of subjects between 7 to 15 years obtained a value of $119.77^{\circ}$ Standard Deviation being 5.4. The values in our study are similar to his findings. Other values of angle NSAr established by Jarvinen are $120.5^{\circ}$ with standard deviation of $4.5^{\circ}$ in Class II malocclusion and $119.77^{0}$, Standard Deviation $5.4^{0}$ in Class III malocclusion. The NSAr angle of total sample was found to be 121.040. It is seen that values of NSAr are less in both Class II and Class III groups as compared to values for normal, in both male and female groups of study. The difference is less marked in Class II group than that of Class III group. This difference in between normal and Class III groups is statistically significant, both in males and females.

In our study, values of NSAr are greater in Class III cases. This is similar to Bjorks findings. SeppoJarvinen concluded that 14 to $40 \%$ of variation of angle SNA could be due to variation of NSAr angle. The values of ' $r$ ' in present study are comparable to Jarvinens value. Value of ' $r$ ' in its normal occlusion group; but not statistically significant. Low correlation of ' $r$ ' in Class II division I and Class III group indicates failure of compensatory mechanism to counteract the defect. Bishara in 1982 stated that rotation of SN plane 
can affect the value of NSAr. He showed that when SN plane rotates clockwise NSAr decreases, and SNA increases and when SN plane rotates counter clockwise NSAr increases and SNA decreases.

Values of angle NSAr in our studies are normal in class II and in class III group. They are less than normal in both class II and class III groups as compared to normal. The difference is less marked in class II group than in class III group. The difference is statistically significant in class III group. In a sample of 170 subjects a study was conducted to assess morphological association between the angles by Dr J.M.H. Dibbets. He stated that the cranial base provided a framework for maxilla to build upon, the middle face created characteristic difference in three classes of Angle and not the mandible.

In a study of 80 subjects by $\mathrm{H}$. Ravanmehr ${ }^{7}$ from three occlusion groups, maxillary prognathism in relationship to SNA and NSAr and their relationship to each other were measured. Their results showed that SNA is influenced by cranial base angle. The craniofacial features of 49 Japanese and 75 Caucasian girls with class II div I malocclusion were analysed by Nobuyuki et al. ${ }^{8}$ from lateral cephalograms and morphological difference between both the races were examined. The mean anterior and total cranial base length (N-Ar) were base length (S-Ar) and saddle angle (NSAr) did not show significant difference between the groups.

Yassir. $A^{9}$ in his study of 143 subjects concluded that saddle angle was affected by gender difference more than the sagittal skeletal class difference. Lateral cephalograms of 108 subjects from Indian population were divided into three categories according to value of NSAr. Group by Dr Amit Bhattacharya, Amarjeet Singh and Others ${ }^{10}$ Group A had values of NSAr more than 1250, Group B had values between $120-125^{\circ}$ and Group C had values of NSAr less than $120^{\circ}$. Their study showed highly significant negative correlation between two angles. The cranial base angle seemed to influence the mandible more than the maxilla as revealed by a stronger negative correlation between angle SNB and NSAr than with angle SNA.

They concluded that SNB angle plays a prominent part in impelling lower jaw location. Decrease in SNB angle results in clockwise gyration of lower jaw. Lower jaw relatively tends to result in alteration from class III to class II with advancement in decrease in SNB angle and vice versa. Dhopatkar et al. ${ }^{11}$ carried out a retrospective cephalometric study to examine the contribution of cranial base angle in four groups of malocclusion as classified by British standard institution. Results showed that cranial base flexion does not play a vital role in determining malocclusion.

Sandesh Hegde and others ${ }^{12}$ in their study of pretreatment lateral cephalograms of 112 subjects were categorised into three classes and studied for N-S-Ar (saddle angle) S-Ar-Go (articulare angle); S-Ar (posterior cranial base length.) Their results showed that N-S-Ar and S-Ar-GO and also S-Ar did not vary significantly in all three classes. N-S-Ar and S-Ar-GO angles have shown a significant negative correlation in any skeletal malocclusion pattern.

Ibraham Alshaharani ${ }^{13}$ et al. conducted a study on 100 adult Saudi patients between 17 and 22 years which revealed considerable variation in the anterior and posterior cranial base lengths, anterior and posterior facial heights, ramus height and mandibular length. Male measurements in contrast to Jarabak's values showed noteworthy variation in articulare angle.

In a systematic review of morphological character of skull base and concomitant development of malocclusion by Almeida and Ravelia ${ }^{14}$, it was observed that a more obtuse angle at skull base in association or not with a greater anterior length of cranial base can contribute to the development of class II div I malocclusion.

A more acute angle at the base of skull can contribute to a more anterior position of mandible and development of class III malocclusion. ${ }^{15}$

A study was done by Nancy Ajwa et al. regarding the controversy over the impact of gender on facial soft tissue thickness (FSTT). Therefore, she planned to evaluate and compare the FSTT of 221 individuals in which 114 were males and 107 were females. This study was conducted in Saudi population who had various malocclusions. Lateral cephalographs included cases from class I (84), class II division 1 (42), class II division 2 (33), and class III (62). Cases from different malocclusions were given almost equal considerations. Burstone analysis with six linear measurements for FSTT was observed on these lateral cephalographs. ${ }^{16}$

Author observed cases with gender preference in that male cases with class I malocclusion displayed greater FSTT in that highly significant data regarding FSTT was observed at the glabella. FSTT with decreasing value was observed with upper and lower lip and sub-labiomental sulcus region. Male cases with class II division 1 malocclusion depicted a sequential alteration in FSTT at subnasal area, lower lip and sub-labiomental sulcus region. No significant difference was observed with FSTT for both the genders for class II division 2 and class III malocclusion cases. ${ }^{17}$

These findings were of substantial variations in facial structures of Saudi population between both the genders and would be of boundless assistance for diagnosis and treatment planning of orthodontic cases of malocclusion in Saudi population. ${ }^{18,19}$

\section{CONCLUSIONS}

Marked part of variation in SNA angle is to be explained by variation in NSAr angle. Large NSAr angle is associated with facial retrognathism and small NSAr with facial prognathism. Normal value of SNA for an individual degree of facial prognathism should be determined individually. As the value of SNA is affected by configuration of cranial base, it should be used with caution especially if NSAr is abnormal.

Data sharing statement provided by the authors is available with the full text of this article at jemds.com.

Financial or other competing interests: None.

Disclosure forms provided by the authors are available with the full text of this article at jemds.com.

\section{REFERENCES}

[1] Wylie WL. Assessment of anteroposterior dysplasia. Angle Orthodontics 1947;17(3):97-109. 
[2] Bjork A. Nature of facial prognathism and its relation to normal occlusion of teeth. Am J Orthod 1951;37(2):10624.

[3] Enlow DH, Pfister C, Richardson E, et al. An analysis of black and caucasian craniofacial patterns. Angle Orthod 1982;52(4):279-87.

[4] Jarvinen S. Relation of the SNA angle to the NSAr angle in excellent occlusion and in malocclusion. Am J Orthod 1982;81(3):245-8.

[5] Sidhu SS, Sundrann KR. Cephalomietric profile of AryoDravidlans-II. J Ind Orthod Soc 1989;20:90.

[6] Jarvinen S. Saddle angle and maxillary rognathism. Radiographic analysis of association between NSAr and SNA angles. Br J Orthod 1984;11 (4):209-13.

[7] Ravanmehr H. The anteroposterior relationship of maxilla with saddle. Angle Journal of Dental medicine 1998:111(4).

[8] Ishii N, Deguchi T, Hunt NP. Morphological difference between Japanese and caucasian girls with class II division 1 malocclusion. Eur J Orthod 2002;24(1):61-7.

[9] Yassir YA. Saddle angle and its relationship with maxillary and mandibular length. Iraqui Orthod J 2009;5(1):14-6.

[10] Bhattacharya A, Bhatia A, Patel D, et al. Evaluation of relationship between cranial base angle and maxillofacial morphology in Indian population: a cephalometric study. J Orthod Sci 2014;3(3):74-80.

[11] Dhopatkar A, Bhatia S, Rock P, et al. An investigation into relationship between the cranial base angle and malocclusion. IJBAMR 2014;4(1):324-48.
[12] Hegde SS, Revankar A, Patil AK. Evaluating condylar position in different skeletal malocclusion patterns: a cephalometric study. APOS Trends in Orthodontics 2015;5(3):111-5.

[13] Alshaharani I, Kamran MA, Alhaizaey A, et al. Evaluation of skeletal variations and establishments of cephalometric norms in Saudi sub population using Bjork Jaraback's analysis. Pak J Med Sci 2018;34(5):1104-9.

[14] De Almedia KCM, Raveli TB, Vieria CIV. Influence of the cranial base flexion on class I, class II and class III malocclusion: a systematic review. Journal of Orthodontics 2017;22(5):56-66.

[15] Gunenkova IV, Samoylova NV, Bondarets AY. Optimization of diagnostics and orthodontic treatment planning in children and adolescents with multiply adentia. Stomatologiia (Mosk) 2015;94(3):61-6.

[16] Perović T, Blažej Z. Male and female characteristics of facial soft tissue thickness in different orthodontic malocclusions evaluated by cephalometric radiography. Med Sci Monit 2018;24:3415-24.

[17] Ardani IGAW, Willyanti I, Narmada IB. Correlation between vertical components and skeletal class II malocclusion in ethnic Javanese. Clin Cosmet Investig Dent 2018;10:297-302.

[18] Al-Azemi R, Al-Jame B, Årtun J. Lateral cephalometric norms for adolescent Kuwaitis: soft tissue measurements. Med Princ Pract 2008;17(3):215-20.

[19] Felemban NH. Correlation between cervical vertebral maturation stages and dental maturation in a Saudi sample. Acta Stomatol Croat 2017;51(4):283-9. 